\title{
Relapsing polychondritis and otologic findings
}

\author{
Serhan Derin ${ }^{1}$, Abdulkadir Oran ${ }^{2}$, Fatma Demirkuru ${ }^{3}$, Selcuk Ucar ${ }^{4}$ \\ ${ }^{1}$ Department of Otorhinolaryngology, Mugla Sitki Kocman University Faculty of Medicine, Mugla, Turkey; \\ ${ }^{2}$ Department of Otorhinolaryngology, Manisa State Hospital, Manisa, Turkey; \\ ${ }^{3}$ Department of Otorhinolaryngology, Seka State Hospital, Kocaeli, Turkey; \\ ${ }^{4}$ Department of Otorhinolaryngology, Corlu Tekirdag State Hospital, Tekirdag, Turkey
}

\begin{abstract}
Relapsing polychondritis is a cartilage tissue disease characterized by inflammatory and destructive episodes. Elastic cartilage of the ear and nose, hyaline cartilage of the joints, hyaline cartilage of vertebra and trachea are the main involvement areas. Also organs having proteoglycan structure such as eyes, heart, blood vessels, and the inner ear can be affected. In this article otologic findings of a 54-year-old male patient with a diagnosis of relapsing polychondritis were presented and discussed in the light of the literature.
\end{abstract}

Key words: Polychondritis; relapsing; sensorineural hearing loss.

$\mathrm{R}$ elapsing polychondritis is a disease coursing with recurrent inflammation of the organs with cartilaginous structures, and organ deformations developed secondary to these inflammatory attacks [1]. It was firstly described by Jaksch-Wartenhorst in 1923. Frequently middle-aged adults are affected. In the USA its median annual incidence is 3.5 per million [2]. Its pathogenesis is not determined completely. Chondritis most frequently involves external ear. In this article, symptoms of the relapsing polychondritis observed in ENT practice have been discussed together with a case presentation.

\section{CASE REPORT}

A 54-year-old male patient consulted to our outpatient clinic with complaints of priorly swelling, erythema of the external ear, then eye redness, and arthralgia since 7 months. With time hearing loss was added to these complaints. It was learnt that the patient was treated with the diagnosis of corneal ulcer, and episcleritis. On her physical examination edematous, and inflamed ear lobes, and external auditory canal were observed. However ear lobule was not involved (Figure 1). Bilateral tympanic membranes were intact. Conjunctivas were hyper- 


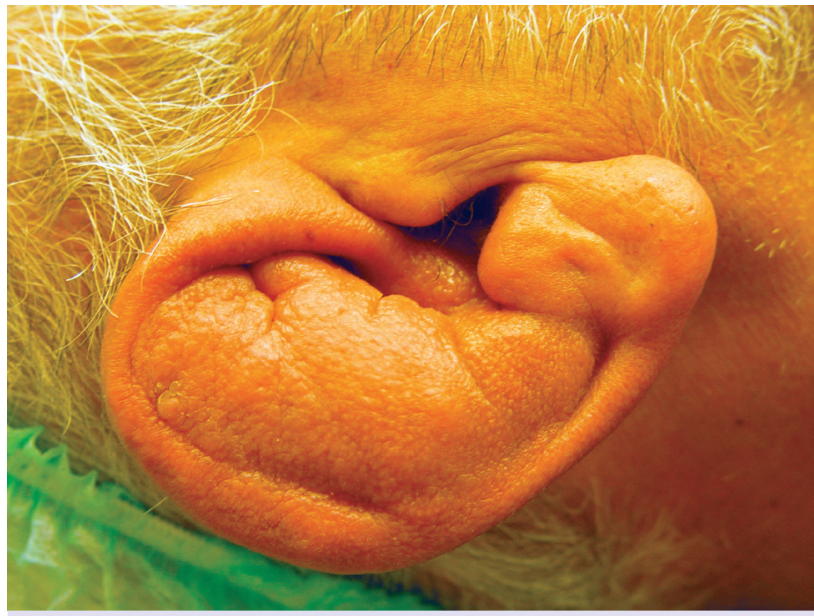

FIGURE 1. Deformed right pinna observed during an acute attack.

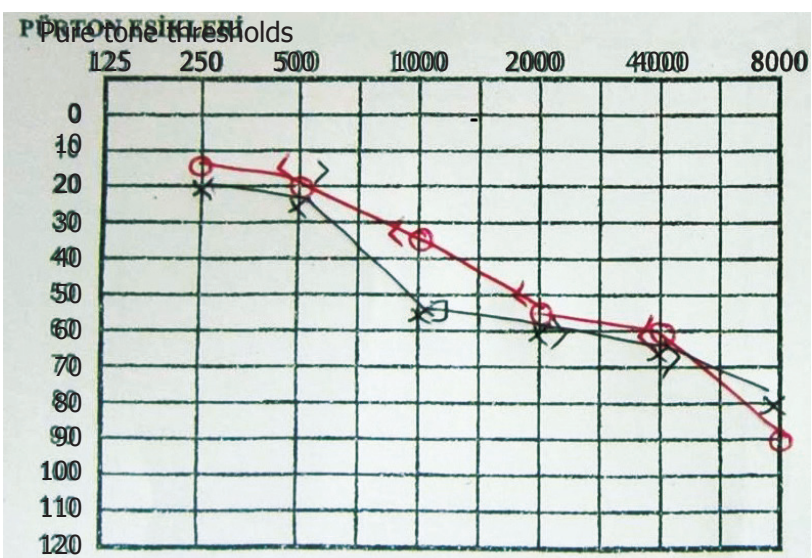

FIGURE2. High, and mid-frequency sensorineural hearing loss.

emic, and edematous. Nasal septum, and cavity appeared to be normal. Biochemical tests revealed increased sedimentation rate $(58 \mathrm{~mm} / \mathrm{h})$, and CRP level. (2.67) Total Ig E was $434 \mathrm{ku} / \mathrm{L}$. Autoantibody panel, bleeding profile, and other biochemical test results were unremarkable. On audiological examinations bilateral type A tympanogram pattern, sensorineural hearing loss of $51 \mathrm{~dB}$ in the left, and of $43 \mathrm{~dB}$ in the right ear was observed (Figure 2). Biopsy material was resected from the right helical cartilage. Cutaneous, and subcutaneous tissue were quiet edematous, and helical cartilage was very fragile. Postoperative healing process was completed

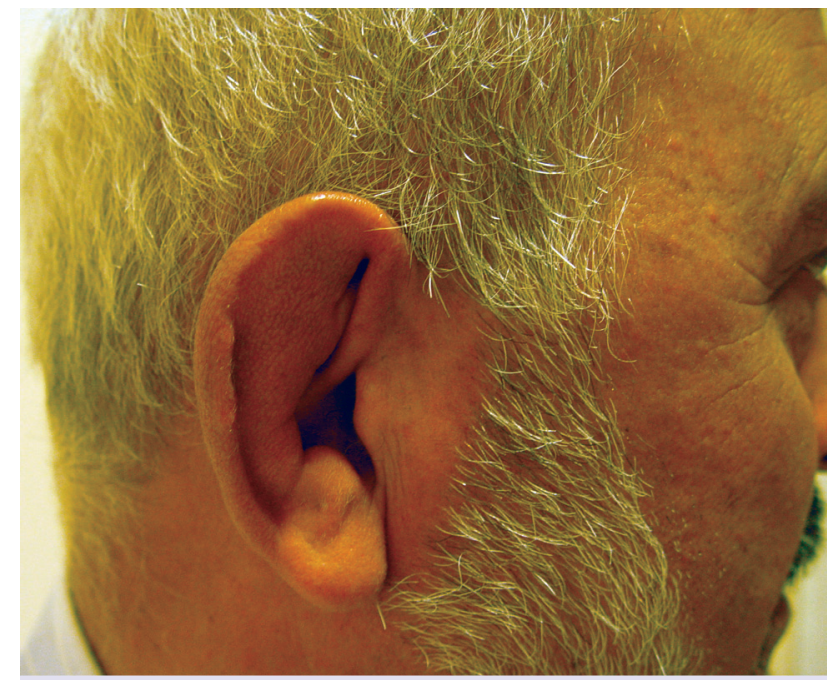

FIGURE 3. Right pinna returned to its normal baseline appearance following medical therapy.

without any delay. Histopathology report indicated acute exacerbation of chronic perichondritis. Initially administered high-dose prednisolon therapy were tapered to maintenance doses with time. The patient attended routine control visits, and his ear lobe gained its normal appearance at 6. month of the medical therapy (Figure 3). However his hearing loss did not recover.

\section{DISCUSSION}

Relapsing polychondritis is a multisystemic disease which courses with relapses, and causes progressive destruction of the cartilage tissue [3]. Although specific laboratory test for relapsing polychondritis is not available, most frequently increased sedimentation rate, and CRP levels are observed. In 50\% of the cases, thrombocytosis, leukocytosis, and normochromic normocytic anemia are encountered. Increased urinary levels of acid mucopolysaccharides, and in the blood samples antibodies developed against type 2 collagen can be detected. In our case, we typically detected increased sedimentation rate, and CRP levels. Its diagnostic algorithm was described in 1976 by McAdam et al. Diagnostic criteria include bilateral auricular chondritis, seronegative polyarthritis, nasal chondritis, ocular inflammation, respiratory system chondritis, and audiovestibular destruction. Accordingly, positivity of at least three 
criteria or treatment response to steroids and/or dapsone, presence of chondritis in two or more than two different regions are sufficient to establish the diagnosis of relapsing polychondritis [1]. Relapsing polychondritis most frequently (89\%) presents with auricular involvement. Bilateral involvement is seen in $95 \%$ of the cases $[1,4]$. Ear lobe is frequently painful, hyperemic, and lobulated. Since ear lobule does not contain cartilaginous structure, it remains intact. Articular, and ocular findings previously thought to be meaningless in most of the cases have been clearly understood to be the components of relapsing perichondritis when auricular perichondritis became manifest. Our case was previously followed up with the diagnosis of episcleritis, however this symptom had not suggested the diagnosis of relapsing polychondritis. These symptoms regress spontaneously within days, rarely weeks, and relapses at varying intervals. At every episode cartilaginous destruction occurs, and deforms the pinna. Conductive, and sensorineural hearing loss are seen in cases with relapsing polychondritis [4-6]. Also in our case, in addition to histopathologic diagnosis, bilateral auricular chondritis, ocular findings, seronegative arthritis, sensorineural type hearing loss, and response to steroid therapy were detected. In $40 \%$ of the cases, audiovestibular findings are observed [2]. Most frequently, bilateral or unilateral sensorineural type hearing loss is seen. Mechanism of the destructive changes in the internal ear are not clearly known, but involvement of the internal ear with the inflammatory process has been implicated. Antilabyrinthine autoantibodies have been observed in some cases with relapsing polychondritis [7]. Though conductive type hearing loss is associated with serous otitis, and chronic otitis frequently secondary to involvement of the eustachian tube, it can be also related to the involvement of the external ear canal [8]. In the treatment, main medication is a corticosteroid. Treatment starts with initial daily loading dose of $15 \mathrm{mg} / \mathrm{kg} /$ day which is tapered stepwise, and pre- scribed based on the activity, and severity of the disease or it can be administered as a maintenance dose. In our case following a bolus dose of a steroid, maintenance dose was given for a period of 6 months. At the end of the treatment auricular edema, and hyperemia regressed. However audiologic gain could not be obtained. Dapsone, colchicine, and immunosuppressives can be also used for its treatment. In conclusion, this clinical condition which progresses with multisystem involvement, due to its characterization by audiologic findings, and especially involvement of the pinna can confront otorhinolaryngology specialists who usually make initial diagnosis.

Conflict of Interest: No conflict of interest was declared by the authors.

Financial Disclosure: The authors declared that this study has received no financial support.

\section{REFERENCES}

1. McAdam LP, O'Hanlan MA, Bluestone R, Pearson CM. Relapsing polychondritis: prospective study of 23 patients and a review of the literature. Medicine (Baltimore) 1976;55:193-215. CrossRef

2. Puéchal X, Terrier B, Mouthon L, Costedoat-Chalumeau N, Guillevin L, Le Jeunne C. Relapsing polychondritis. Joint Bone Spine 2014 Mar;81:118-24. CrossRef

3. Trentham DE, Le CH. Relapsing polychondritis. Ann Intern Med 1998;129:114-22. CrossRef

4. Damiani JM, Levine HL. Relapsing polychondritis-report of ten cases. Laryngoscope 1979;89(6 Pt 1):929-46.

5. Michet CJ Jr, McKenna CH, Luthra HS, O'Fallon WM. Relapsing polychondritis. Survival and predictive role of early disease manifestations. Ann Intern Med 1986;104:74-8. CrossRef

6. Bachor E, Blevins NH, Karmody C, Kühnel T. Otologic manifestations of relapsing polychondritis. Review of literature and report of nine cases. Auris Nasus Larynx 2006;33:135-41. CrossRef

7. Issing WJ, Selover D, Schulz P. Anti-labyrinthine antibodies in a patient with relapsing polychondritis. Eur Arch Otorhinolaryngol 1999;256:163-6. CrossRef

8. Estes SA. Relapsing polychondritis. A case report and literature review. Cutis 1983;32:471-6. 